\title{
Improvement of Mathematics About Plane Figures Through Realistic Mathematics Education (RME) Approach To Fourth Grade Students of SDN Karangrejo In Academic Year Of 2019/2020
}

\author{
Rakai Paksi Hinu Sadhewo', Wahyudi², Ratna Hidayah ${ }^{3}$ \\ Sebelas Maret University \\ sadheworphs@gmail.com
}

\section{Article History}

accepted 01/06/2020

approved 01/07/2020

published 01/08/2020

\begin{abstract}
The study aimed: (1) to describe the step of RME approach, (2) to improve mathematics, and (3) to describe obstacles and solutions. It was a collaborative classroom action research carried out in three cycles. The subjects were teachers and students. Data collection techniques were observation, interviews, and tests. Data analysis techniques included data reduction, data presentation, and drawing conclusions. The results showed that: (1) the steps to the application of RME approach were understanding contextual problems, explaining contextual problems, solving contextual problems, comparing and discussing answers, also drawing conclusion; (2) the RME approach improved mathematics about plane figures. It was proven by the increasing of mastery learning: $87.50 \%$ in the first cycle, $90.62 \%$ in the second cycle, and $93,75 \%$ in the third cycle; (3) the obstacles were: there were a few students asking questions, the students were less active in responding the results of th discussion, the students were less conducive during discussion, the teacher drew the conclusion. The solutions were the teacher gave motivation to the students to ask questions, the teacher encouraged the students to respond to each other during presentation, the teacher kept the students engaged in a group, and the teacher guided the students to summarize the results of the discussion.
\end{abstract}

Keywords: Realistic Mathematics Education, Plane Figures

Abstrak: Tujuan penelitian ini yaitu: (1) mendeskripsikan langkah-langkah pendekatan $R M E$, (2) meningkatkan pembelajaran matematika, (3) mendeskripsikan kendala dan solusi. Penelitian ini merupakan penelitian tindakan kelas kolaboratif yang dilaksanakan dalam tiga siklus. Subjek penelitian ini adalah guru dan siswa. Teknik pengumpulan data menggunakan observasi, wawancara, dan tes. Analisis data meliputi reduksi data, penyajian data, dan kesimpulan. Hasil penelitian menunjukkan bahwa: (1) penerapan pendekatan RME dilaksanakan dengan langkah memahami masalah kontekstual, menjelaskan masalah kontekstual, menyelesaikan masalah kontekstual, membandingkan dan mendiskusikan jawaban, serta menyimpulkan; (2) pendekatan RME dapat meningkatkan pembelajaran matematika tentang bangun datar, terbukti dengan adanya peningkatan persentase ketuntasan siswa, yaitu pada siklus $I=87,50 \%$, siklus $I I=90,62 \%$, dan siklus $I I I=93,75 \%$; (3) kendala penelitian ini yaitu: masih sedikit siswa yang bertanya, siswa kurang aktif memberikan tanggapan diskusi, siswa kurang tertib saat berdiskusi, penyimpulan didominasi oleh guru. Solusinya yaitu: guru memotivasi siswa untuk bertanya, guru mengondisikan siswa saat presentasi untuk saling menanggapi, guru mengondisikan siswa saat berkelompok, guru membimbing siswa untuk menyimpulkan hasil diskusi.

Kata kunci: Realistic Matematics Education, Bangun Datar 


\section{PENDAHULUAN}

Pembelajaran matematika SD idealnya agar lebih bermakna, siswa dapat dibimbing dan dibiasakan untuk memperoleh pemahaman materi melalui pengalaman dan pengetahuan yang dikembangkan oleh siswa sendiri, hal ini karena setiap masingmasing siswa memiliki potensi kemampuan berpikir yang berbeda-beda. Dengan pembiasaan siswa untuk mengembangkan pengalaman dan pengetahuan diharapkan dapat melatih cara berpikir siswa secara sistematis, logis, kritis, kreatif dan konsisten (Rusmana, 2016: 2; Wahyudi, 2015: 68).

Berdasarkan hasil Penilaian Tengah Semester kelas IV pada mata pelajaran Matematika semester ganjil tahun ajaran 2019/2020, di dapatkan nilai rata-rata yaitu 68 dengan nilai tertinggi 78 dan nilai terendah 56. Kriteria Ketuntasan Minimal (KKM) mata pelajaran Matematika kelas IV SDN Karangrejo yaitu 70. Jumlah siswa kelas IV SDN Karangrejo pada semester ganjil tahun ajaran 2019/2020 berjumlah 15 siswa, siswa yang telah mencapai KKM yaitu sebanyak 5 siswa atau sebesar $33 \%$, sedangkan siswa yang belum mencapai KKM sebanyak 10 siswa atau sebesar $67 \%$. Berdasarkan hasil observasi dan wawancara dengan guru kelas IV SDN Karangrejo ditemukan kondisi saat proses pembelajaran sebagai berikut: (1) guru masih menggunakan pendekatan teacher centered, (2) guru tidak menggunakan media konkret saat pembelajaran, serta (3) siswa kurang aktif dalam pembelajaran. Oleh karena itu, diperlukan perbaikan pembelajaran pada mata pelajaran Matematika. Perbaikan tersebut dapat dilakukan dengan penerapan pendekatan $R M E$.

Materi yang dibahas dalam penelitian adalah materi Keliling dan Luas Bangun Datar sesuai dengan KD 3.9 menjelaskan dan menentukan keliling dan luas persegi, persegi panjang, dan segitiga serta hubungan pangkat dua dengan akar pangkat dua, yang bersumber dari buku siswa karangan Suparmin (2016: 109-116). Hosnan (2016: 18) berpendapat bahwa pembelajaran merupakan suatu proses menciptakan kondisi yang kondusif agar terjadi interaksi komunikasi belajar mengajar antara guru, peserta didik, dan komponen pembelajaran lainnya untuk mencapai tujuan pembelajaran. Matematika adalah ilmu dasar yang berguna untuk membantu siswa dalam memecahkan masalah, baik dalam Matematika itu sendiri atau ilmu lain pada kehidupan sehari-hari (Lambertus, 2014: 602).

Pembelajaran matematika tentang keliling dan luas daerah bangun datar kelas IV sekolah dasar adalah kegiatan belajar mengajar pada siswa dalam tahap perkembangan operasional konkret mengenai bahan kajian matematika yang dapat diukur kualitas pembelajarannya dengan melihat proses dan hasil belajar yang bertujuan untuk melatih siswa berpikir sistematis, logis, kritis, kreatif, dan konsisten, serta memperoleh hasil belajar berupa perubahan pada diri siswa, khususnya pada materi keliling dan luas persegi, persegi panjang, dan segitiga.

Freudenthal (Webb, Kooij, \& Geist, 2011: 47) mengungkapkan bahwa prinsip pendekatan RME keterlibatan dalam matematika untuk siswa harus mulai dalam konteks yang bermakna. RME tidak hanya ditunjukkan karena hubungannya dengan konteks dunia nyata, tetapi terkait dengan penekanan RME yang menawarkan masalah siswa yang bisa dibayangkan, sehingga siswa dapat mengetahui matematika yang dibangun dengan sudut pandangnya. Mengenai pendekatan RME, Searle, Barmby \& Sumitro (Hidayat \& Iksan, 2015: 2440) mendefinisikan RME sebagai pembelajaran kontekstual, yang berarti anak-anak belajar matematika melalui partisipasi untuk dipecahkan masalah nyata dalam konteks yang bermakna. Wahyudi (2015: 32-33) mengemukakan langkah-langkah RME yaitu: (1) memahami masalah/konteks, (2) menjelaskan masalah kontekstual, (3) menyelesaikan masalah kontekstual, (4) membandingkan dan mendiskusikan jawaban, (5) menyimpulkan. 
Cholifah \& Purwanto (2014: 2) berpendapat bahwa, media konkret adalah media/alat yang nyata (benar-benar ada) berwujud dan dapat dilihat, diraba, dan dirasakan menggunakan alat indera yang memudahkan dalam penyampaian pesan dari guru ke siswa. Menurut Asyhar (2011: 54), media konkret adalah benda yang dapat dilihat, didengar, atau dialami oleh peserta didik sehingga memberikan pengalaman langsung kepada mereka.

Penerapan pendekatan $R M E$ adalah pendekatan pembelajaran matematika yang mengaitkan antara matematika dengan aktivitas atau permasalahan manusia yang nyata dan benar-benar dialami oleh siswa dalam kehidupan sehari-hari untuk dipecahkan dalam konteks yang bermakna dan memberikan pengalaman langsung pada siswa maka langkah pendekatan $R M E$ dimodifikasi dengan sarana pendukung yaitu media konkret.

Berdasarkan uraian di atas, dapat dirumuskan masalah sebagai berikut: (1) bagaimana langkah penerapan pendekatan $R M E$ dalam peningkatan pembelajaran matematika tentang bangun datar pada siswa kelas IV SD Negeri Karangrejo tahun ajaran 2019/2020?, (2) apakah penerapan pendekatan RME dapat meningkatkan pembelajaran matematika tentang bangun datar pada siswa kelas IV SD Negeri Karangrejo tahun ajaran 2019/2020?, (3) Apa kendala dan solusi dalam penerapan pendekatan RME dalam peningkatan pembelajaran matematika tentang bangun datar pada siswa kelas IV SD Negeri Karangrejo tahun ajaran 2019/2020?.

\section{METODE}

Penelitian ini dilaksanakan di SDN Karangrejo yang berlangsung dari bulan November 2019 sampai Maret 2020. Subjek penelitian ini adalah guru dan siswa kelas IV yang berjumlah 16 siswa yang terdiri dari 8 siswa laki-laki dan 8 siswa perempuan. Penelitian tindakan kelas ini dilakukan secara kolaboratif. Data yang digunakan berupa data kualitatif yaitu penerapan pendekatan $R M E$ dan data kuantitatif yaitu pada tes hasil belajar siswa dalam mata pelajaran matematika. Teknik pengumpulan data menggunakan observasi, wawancara, dan tes. Observasi pada penelitian ini dilakukan pada saat guru dan siswa yang sedang melaksanakan proses pembelajaran untuk mendapatkan data tentang aktivitas guru, respon dan tingkat partisipasi siswa. Observasi ini dilakukan oleh peneliti dan teman sejawat. Wawancara dilaksanakan secara terstruktur dengan lembar wawancara yang telah disusun peneliti dan dilaksanakan setelah proses pembelajaran selesai. Narasumber wawancara ini yaitu guru dan beberapa siswa guna memperoleh data tentang proses pembelajaran melalui penerapan $R M E$ dalam pembelajaran Matematika. Tes sebagai alat penilaian tertulis berupa tes yang dilaksanakan setelah proses pembelajaran yang terdiri dari pilihan ganda, isian, dan uraian untuk mendapatkan data hasil belajar matematika materi bangun datar kelas IV semester II. Validitas data menggunakan triangulasi teknik dan sumber. Teknik analisis data meliputi reduksi data, penyajian data, dan kesimpulan.

Indikator kinerja penelitian ini adalah penerapan pendekatan RME dan hasil belajar matematika tentang bangun datar $(\mathrm{KKM}=72)$ ditargetkan mencapai $85 \%$. Adapun prosedur penelitian ini menggunakan model penelitian tindakan kelas yang terdiri dari empat tahapan, yaitu (1) perencanaan, (2) pelaksanaan, (3) observasi, (4) refleksi.

\section{HASIL DAN PEMBAHASAN}

Penelitian ini dilaksanakan tiga siklus dengan lima kali pertemuan. Langkahlangkah pendekatan $R M E$ yang sudah dilaksanakan pada III siklus yaitu: (a) memahami masalah kontekstual, (b) menjelaskan masalah kontekstual, 
(c) menyelesaikan masalah kontekstual, (d) membandingkan dan mendiskusikan jawaban, (e) menyimpulkan. Langkah pembelajaran tersebut mengacu pada langkahlangkah yang dikemukakan oleh Shoimin (2014: 150), Wahyudi (2015: 32-33), dan Jazuli (Abujina, Bey, \& Sahidin, 2013: 6) yang kemudian peneliti melakukan modifikasi langkah tersebut dengan menggunakan media konkret sebagai sarana pendukung penerapan pendekatan RME.

Hasil observasi penerapan pendekatan RME mengalami peningkatan pada setiap siklusnya hingga mencapai kinerja penelitian yang ditargetkan sebesar $85 \%$ yang dapat dilihat pada tabel 1 .

Tabel 1 Perbandingan Antarsiklus Penerapan Pendekatan Realistic Mathematics Education terhadap Guru dan Siswa

\begin{tabular}{lccccccccc}
\hline \multirow{2}{*}{$\begin{array}{l}\text { Langkah Penerapan } \\
\text { Pendekatan RME }\end{array}$} & $\begin{array}{c}\mathrm{G} \\
(\%)\end{array}$ & $\begin{array}{c}\mathrm{S} \\
(\%)\end{array}$ & $\begin{array}{c}\mathrm{G} \\
(\%)\end{array}$ & $\begin{array}{c}\mathrm{S} \\
(\%)\end{array}$ & $\begin{array}{c}\mathrm{G} \\
(\%)\end{array}$ & $\begin{array}{c}\mathrm{S} \\
(\%)\end{array}$ & $\begin{array}{c}\mathrm{G} \\
(\%)\end{array}$ & $\begin{array}{c}\mathrm{S} \\
(\%)\end{array}$ \\
\hline $\begin{array}{l}\text { Memahami masalah } \\
\text { kontekstual dengan } \\
\text { media konkret }\end{array}$ & 82,50 & 84,16 & 88,33 & 87,50 & 91,67 & 90,00 & 87,50 & 87,22 \\
\hline $\begin{array}{l}\text { Menjelaskan masalah } \\
\text { kontekstual dengan } \\
\text { media konkret }\end{array}$ & 87,50 & 87,50 & 89,17 & 88,33 & 91,67 & 91,67 & 89,45 & 89,17 \\
\hline $\begin{array}{l}\text { Menyelesaikan masalah } \\
\text { dengan media konkret }\end{array}$ & 88,90 & 88,89 & 91,67 & 90,28 & 94,44 & 91,67 & 91,67 & 90,28 \\
\hline $\begin{array}{l}\text { Membandingkan dan } \\
\text { mendiskusikan jawaban }\end{array}$ & 86,67 & 81,67 & 87,50 & 85,00 & 90,00 & 88,33 & 88,06 & 85,00 \\
\hline $\begin{array}{l}\text { Menyimpulkan } \\
\text { Rata-rata }\end{array}$ & 86,30 & 87,50 & 90,47 & 88,68 & 92,85 & 90,47 & 89,87 & 88,88 \\
\hline
\end{tabular}

Berdasarkan tabel 1 dapat diketahui bahwa persentase penerapan pendekatan Realistic Mathematics Education (RME) terhadap guru dan siswa mengalami peningkatan. Rata-rata hasil observasi terhadap guru pada siklus I =86,37\%, siklus II $=89,42 \%$ dan siklus III $=92,13 \%$. Rata-rata hasil observasi terhadap siswa pada siklus $\mathrm{I}=85,95 \%$, siklus $\mathrm{II}=87,95 \%$ dan siklus $\mathrm{III}=90,43 \%$.

Pembelajaran Matematika tentang bangun datar mengalami berbagai perbaikan pada proses pembelajaran untuk mencapai hasil yang maksimal. Perbandingan antarsiklus pembelajaran Matematika tentang bangun datar dapat dilihat pada tabel 2.

Tabel 2 Perbandingan Antarsiklus Hasil Belajar Siswa Matematika tentang Bangun Datar

\begin{tabular}{llllll}
\hline \multirow{2}{*}{ Keterangan } & \multicolumn{2}{c}{ Siklus I } & \multicolumn{2}{c}{ Siklus II } & Siklus III \\
\cline { 2 - 6 } & Pert. 1 & Pert. 2 & Pert. 1 & Pert. 2 & Pert. 1 \\
\hline Nilai Tertinggi & 93 & 93 & 90 & 93 & 97 \\
\hline Nilai Terendah & 23 & 30 & 40 & 50 & 63 \\
\hline Rata-rata & 76,43 & 77,18 & 79,25 & 81,66 & 84,56 \\
\hline Tuntas (\%) & 87,50 & 87,50 & 87,50 & 93,75 & 93,75 \\
\hline Belum Tuntas (\%) & 12,50 & 12,50 & 12,50 & 6,25 & 6,25 \\
\hline
\end{tabular}

Berdasarkan tabel 2 dapat dilihat bahwa hasil belajar siswa meningkat mulai dari siklus I sampai dengan siklus III. Siklus I pertemuan 1 nilai tertinggi yang diperoleh sebesar 93 , nilai terendah sebesar 23 , rata-rata nilai siswa 76,43 dengan siswa tuntas 
sebanyak 14 siswa dan siswa tidak tuntas sebanyak 2 siswa. Siklus I pertemuan 2 nilai tertinggi yang diperoleh sebesar 93, nilai terendah sebesar 30, rata-rata nilai siswa 77,18 dengan siswa tuntas sebanyak 14 siswa dan siswa tidak tuntas sebanyak 2 siswa. Siklus II pertemuan 1 nilai tertinggi yang diperoleh sebesar 90, nilai terendah sebesar 40, rata-rata nilai siswa 79,25 dengan siswa tuntas sebanyak 14 siswa dan siswa tidak tuntas sebanyak 2 siswa. Siklus II pertemuan 2 nilai tertinggi yang diperoleh sebesar 93, nilai terendah sebesar 50, rata-rata nilai siswa 81,66 dengan siswa tuntas sebanyak 15 siswa dan siswa tidak tuntas sebanyak 1 siswa. Siklus III pertemuan 1 nilai tertinggi yang diperoleh sebesar 97 , nilai terendah sebesar 63 , ratarata nilai siswa 84,56 dengan siswa tuntas sebanyak 15 siswa dan siswa tidak tuntas sebanyak 1 siswa.

Berdasarkan penjelasan di atas, maka dapat disimpulkan bahwa penerapan pendekatan $R M E$ dapat meningkatkan pembelajaran matematika tentang bangun datar yang dilihat dari persentase siswa yang memenuhi ketercapaian target dari siklus I III. Peningkatan pembelajaran ini terjadi karena dalam penerapan pendekatan RME siswa dituntut untuk berfikir kritis, aktif, dan kreatif seperti yang diungkapkan oleh Chotimah (Chisara, dkk., 2018: 66) pendekatan RME dapat menciptakan siswa lebih aktif, kreatif, berfikir, dan berani mengemukakan pendapat, serta dapat membuat suasana pelajaran matematika lebih kreatif dan menyenangkan. Siswa yang berpikir kritis dan kreatif juga akan berdampak pada peningkatan hasil belajar seperti yang dikemukakan oleh Sari dan Retno (2017: 2) siswa yang berfikir semakin kritis dan kreatif akan menjamin ilmu pengetahuan yang diperoleh akan bertahan lebih lama sehingga akan berdampak pada hasil belajar siswa yang semakin meningkat. Penelitian ini sejalan dengan penelitian yang dilakukan Fitriani \& Maulana (2016: 40) dan Tarigan (2017: 5) yang membuktikan bahwa pendekatan RME mampu meningkatkan pembelajaran siswa.

Kendala dalam penelitian ini yaitu: (1) masih sedikit siswa yang berani bertanya, (2) Siswa kurang aktif dalam memberikan tanggapan hasil diskusi, (3) guru kurang bisa membangkitkan motivasi siswa untuk aktif bertanya, (4) guru kurang dalam memberi instruksi siswa lain untuk memperhatikan presentasi kelompok yang sedang maju, (5) siswa kurang tertib saat berdiskusi dengan kelompoknya dan bermain sendiri, (6) masih sedikit siswa yang menanyakan hal-hal yang belum dipahami, (7) beberapa siswa juga mengganggu kelompok lain saat diskusi, (8) penyimpulan didominasi oleh guru, dan (9) kesadaran siswa untuk mencatat hal-hal penting masih kurang. Adapun solusinya yaitu: (1) guru memberikan rangsangan dan motivasi kepada siswa untuk bertanya, (2) guru mengarahkan siswa dan mengondisikan siswa saat presentasi untuk saling menanggapi dan tanya jawab, (3) guru memberikan motivasi siswa agar siswa lebih aktif bertanya, (4) guru lebih tegas dan jelas dalam memberi instruksi siswa lain agar siswa memperhatikan presentasi kelompok yang sedang maju, (5) guru berkeliling dan mengondisikan siswa saat berkelompok, (6) guru merangsang siswa untuk bertanya dengan cara memberikan pertanyaan, (7) guru mendekati dan memberikan teguran untuk mengerjakan dengan kelompoknya, (8) guru mengajak, membimbing dan memancing siswa menggunakan bahasa yang mudah dipahami untuk menyimpulkan hasil diskusi, dan (9) guru mengingatkan siswa pentingnya mencatat yang sudah ditulis di papan tulis agar dapat digunakan untuk belajar kembali dirumah.

Kendala yang sering muncul ialah masih banyak siswa yang enggan bertanya dan berpendapat. Menurut Brain (Yuniati, 2009: 178) rasa malu, takut, rendah diri, dan ketidakpedulian merupakan faktor-faktor yang memaksa siswa untuk tidak bertanya. Salah satu cara untuk mendorong siswa bertanya yaitu dengan menciptakan lingkungan tanya jawab dengan memunculkan rasa ingin tahu siswa sehingga 
mendorong siswa untuk bertanya, seperti yang dikemukakan oleh Indriyanti, Effy dan Yahya (2017: 19) guru membimbing siswa untuk membuat pertanyaan dan memberikan contoh pertanyaan agar siswa mulai berfikir kritis dan mulai membuat pertanyaan. Rasa ingin tahu siswa dapat dirangsang dengan menyebutkan kata petunjuk atau pertanyaan pancingan yang berkaitan dengan materi pelajaran.

\section{SIMPULAN DAN SARAN}

Peningkatan pembelajaran matematika tentang bangun datar melalui pendekatan RME pada siswa kelas IV SDN Karangrejo tahun ajaran 2019/2020 dilaksanakan dengan langkah-langkah: (a) memahami masalah kontekstual, (b) menjelaskan masalah kontekstual, (c) menyelesaikan masalah, (d) membandingkan dan mendiskusikan jawaban, (e) menyimpulkan.

Hasil penelitian penerapan pendekatan RME yaitu dapat meningkatkan pembelajaran matematika tentang bangun datar pada siswa kelas IV SDN Karangrejo tahun ajaran 2019/2020 dengan persentase rata-rata ketuntasan pada siklus $\mathrm{I}=$ $87,50 \%$, siklus $I=90,62 \%$, dan siklus $I I=93,75 \%$.

Berkaitan dengan hasil penelitian yang telah dicapai, peneliti mengajukan saran sebagai berikut: (1) guru lebih meningkatkan kemampuan merangsang siswa untuk bertanya supaya siswa lebih aktif dalam kegiatan pembelajaran, (2) siswa hendaknya lebih bersemangat lagi dan berani untuk mengemukakan pendapatnya dalam menanggapi kelompok lain ataupun bertanya jawab mengenai hal yang belum dipahami dari materi yang dipelajari untuk mendapatkan hasil yang maksimal, (3) sebaiknya sekolah menyediakan fasilitas, sarana, dan prasarana serta mendukung guru untuk berinovasi dalam menggunakan pendekatan dan media pembelajaran untuk meningkatkan kualitas pembelajaran, (4) Peneliti lain sebaiknya membuat kegiatan pembelajaran yang lebih inovatif dan kreatif sesuai dengan perkembangan ilmu pengetahuan yang semakin maju. Salah satunya, yaitu dengan menerapkan pendekatan Realistic Mathematics Education (RME).

\section{DAFTAR PUSTAKA}

Abujina, A., Bey, A., \& Sahidin, L. (2013). Meningkatkan Hasil Belajar Matematika Siswa Kelas VII SMP Negeri 10 Kendari pada Materi Pecahan melalui Pendekatan Realistic Mathematics Education (RME). Jurnal Penelitian Pendidikan Matematika, 1(2), 1-12.

Asyhar, R. (2011). Kreatif Mengembangkan Media Pembelajaran. Jakarta: Referensi Jakarta.

Chisara, C., Hakim, D. L., \& Kartika, H. (2019). Implementasi Pendekatan Realistic Mathematics Education (RME) Dalam Pembelajaran Matematika. Prosiding Sesiomadika, 1(2), 65-72.

Cholifah \& Purwanto. (2014). Penggunaan Media Konkret untuk Meningkatkan Hasil Belajar Matematika tentang Perkalian yang Hasilnya Bilangan Dua Angka pada Siswa Kelas II SDN Benowo IV/124 Surabaya. JPGSD, 02 (01), 1-6.

Fitriani, K., \& Maulana, M. (2016). Meningkatkan Kemampuan Pemahaman Dan Pemecahan Masalah Matematis Siswa SD Kelas V Melalui Pendekatan Matematika Realistik. Mimbar Sekolah Dasar, 3(1), 40-52.

Hidayat, R., \& Iksan, Z. H. (2015). The Effect of Realistic Mathematics Education on Students' Conceptual Understanding of Linear Progamming. Creative Education, 6(22).

Hosnan, M. (2016). Pendekatan Saintifik dan Kontekstual dalam Pembelajaran Abad 21. Bogor: Ghalia Indonesia. 
Indriyanti, Mulyasari, E., \& Sudarya, Y. (2017) Penerapan Pendekatan Saintifik untuk Meningkatkan Keterampilan Bertanya Siswa Kelas V SD. Jurnal Pendidikan Guru Sekolah Dasar. 2 (2), 13-25.

Lambertus, Bey, A., Anggo, M., \& Fahiru. (2014). Developing Skills Resolution Mathematicsal Primary School Students. International Journal of Education and Research, 2(10), 601-614.

Rusmana, T. (2016). Pengaruh Pendekatan Eksploratif dan Kepercayan Diri terhadap Kemampuan Pemecahan Masalah Matematis pada Materi Luas Trapesium dan Layang-Layang (Penelitian Eksperimen terhadap Peserta Didik Kelas VA dan Kelas VB SD Negeri Panjalin Kidul I Kecamatan Sumberjaya Kabupaten Majalengka). Skripsi Tidak Dipublikasikan. Universitas Pendidikan Indonesia, Sumedang.

Sari, P.D. \& Dewi, M.R. (2017). Pengaruh Keterampilan Berpikir Kritis dan Berpikir Kreatif Terhadap Hasil Belajar Mata Pelajaran Ekonomi kelas X IPS 1 di MAN Mojosari. Jurnal Pendidikan Ekonomi, 5 (1), 1-8.

Shoimin, A. (2014). 68 Model Pembelajaran Inovatif dalam Kurikulum 2013. Yogyakarta: Ar-Ruzz Media.

Suparmin. (2016). Matematika untuk SD/MI Kelas IV. Surakarta: CV Mediatama.

Tarigan, D. (2017). Meningkatkan Hasil Belajar Siswa dengan Menggunakan Pendekatan Realistic Mathematics Education (RME) DI KELAS V SD, 2(1), 1-6.

Wahyudi. (2015). Panduan Pembelajaran Matematika Sekolah Dasar (Untuk Guru Calon Guru SD). Surakarta: UNS Press.

Webb, D. C., Van der Kooij, H., \& Geist, M. R. (2011). Design research in the Netherlands: Introducing logarithms using realistic mathematics education. Journal of Mathematics Education at Teachers College, 2(1).

Yunarti, T. (2009). Fungsi dan Pentingnya Pertanyaan dalam Pembelajaran. In Makalah Prosiding disampaikan pada seminar Nasional Matematika Jurusan Pendidikan Matematika FMIPA UNY (Vol. 5). 